\title{
Nanoparticles Loaded Biopolymer as Effective Adsorbent for Adsorptive Removal of Malachite Green from Aqueous Solution
}

\author{
Nirav P. Raval ${ }^{1} \cdot$ Prapti U. Shah ${ }^{1} \cdot$ Nisha K. Shah ${ }^{2}$
}

Received: 21 January 2016 / Accepted: 21 April 2016 /Published online: 12 May 2016

(C) Springer Science+Business Media Singapore 2016

\begin{abstract}
In the present study, the biocompatible nanocomposite (nickel oxide nanoparticles loaded chitin beads (NiO $\mathrm{NPs} / \mathrm{CH})$ ) was synthesized, characterized by using scanning electron microscopy (SEM) and Fourier transform infrared (FT-IR) analysis and then study its prospective application towards adsorption of malachite green (MG) dye. Further, batch studies were conducted to evaluate the adsorption capacity of nanocomposite, and the effects of various parameters, i.e., $\mathrm{pH}$, adsorbate concentration, contact time, dosage of adsorbent and temperature, were investigated. The results revealed that the amount of MG adsorbed on the adsorbent increases with increasing initial dye concentration and by decreasing temperature. The equilibrium $\mathrm{MG}$ adsorption data on $\mathrm{NiO} \mathrm{NPs} / \mathrm{CH}$ were best described by the Langmuir isotherm model. Besides, the adsorption kinetics followed pseudosecond-order rate equation. Thermodynamic parameters such as free energy of adsorption $\left(\Delta \mathrm{G}^{\circ}\right)$, enthalpy $\left(\Delta \mathrm{H}^{\circ}\right)$, and entropy $\left(\Delta \mathrm{S}^{\circ}\right)$ changes were calculated, and the results suggested that the adsorption process was spontaneous and exothermic in nature. Based on the results, it was concluded that the nanocomposite can be sustainably prepared and efficiently used for the adsorptive removal of MG from colored aqueous solutions.
\end{abstract}

Keywords Nickel oxide $\cdot$ Chitin beads $\cdot$ Nanoparticles · Nanocomposite $\cdot$ Malachite green $\cdot$ Sustainably

Nisha K. Shah

nish_chem2004@yahoo.com

1 Department of Environmental Science, School of Sciences, Gujarat University, Ahmedabad, Gujarat 380 009, India

2 Department of Chemistry, School of Sciences, Gujarat University, Ahmedabad, Gujarat 380 009, India

\section{Introduction}

Malachite green (MG) is a water soluble cationic dye that appears as crystalline green powder and it belongs to triphenylmethane category. Though the use of this dye has been banned in several countries and not approved by US Food and Drug Administration, still it is extensively used for the dyeing of cotton, jute, paper, silk, wool, and leather products in many parts of the world. In addition, it is also used as an antiseptic and fungicidal for humans, and as anti-parasitical, antibacterial, and antifungal in aquaculture and commercial fish hatchery industries due to its low cost, ready availability, efficacy, and deficiency of proper substitute [1]. Due to its mutagenic and carcinogenic nature, it can cause severe effects on the nervous system, reproductive system, liver, brain, and kidney $[2,3]$. Apart from causing undesirable health effects, the presence of even very low concentration of MG in the aqueous environment can color large water bodies which decrease photosynthesis by obstructing light penetration and thereby inhibit the growth of aquatic life [4]. Hence, proper treatment of effluent containing MG dye is extremely necessary for the protection of environment and other living organisms.

Many treatment technologies have been applied in order to decolorize $\mathrm{MG}$ from an aqueous medium such as coagulation-flocculation [5, 6], biodegradation [7], photocatalytic degradation [8], sonochemical and sonophotocatalytic degradation [9-11], ozonation [12], and Fenton reagent [13-16]. Among all these techniques, adsorption is regarded as simple, economically manageable, and desirable process for the treatment of industrial effluent due to its high efficiency and ability to separate a wide range of pollutants. Adsorption on activated carbon has been found to be an effective process for removal of dyes, but it was an expensive process as both regeneration and disposal of the 
used carbon are often very difficult. Thus, it was a necessity to identify and develop easily available, economically viable, and highly effective adsorbent for efficient and facile removal of dye.

In recent time, use of biopolymers is increasing for the removal of dye from wastewater. Chitin (poly $[\beta-(1 \rightarrow$ 4)-2-acetamido-2-deoxy- $\beta-D-$ glucopyranose]), a polymer of $N$-acetyl-D-glucosamine, is the most frequently found natural biopolymer in the exoskeleton of marine invertebrates such as shrimps, crabs, prawns, and lobsters. This biopolymer exhibits a high biodegradability, nontoxicity, and adsorption properties [17]. Nickel oxide $(\mathrm{NiO})$ is an important transition metal oxide which can be employed in various fields due to its chemical and thermal stability and environmental benignity [18]. Composites and nanocomposites, refer to materials consisting of at least two phases with one dispersed in another that is called matrix, have attracted increasing research attention. Composites of polymers and nanoparticles can provide many synergistic properties, which are difficult to attain from individual components [19]. In this context, nanocomposite of chitin, a natural biopolymer, and nickel oxide nanoparticle, an important transitional metal oxide, has been synthesized.

In developing countries due to the scarcity of the water resources, it is essential to conserve the water. But on the contrary for their growth, the industrial development is required and hence during the various industrial processes, immense quantity of wastewater is generated. If this wastewater is not treated properly and discharged, then it causes pollution of the natural water streams. Thus, wastewater reuse is an important strategy for conserving water resources. There are various advantages associated with the reuse of wastewater such as reduction in consumption of fresh water, disposal problem which ultimately leads to the secondary pollution of the receiving water bodies, as well as associated treatment cost. In addition, properly treated wastewater can also be used for various purposes like toilet flushing, cooling water, and other applications. But, for the reuse of wastewater, it should be properly treated without creating more pollution.

Therefore, the aim of this study was to synthesize and characterize nickel oxide nanoparticles loaded chitin beads (NiO $\mathrm{NPs} / \mathrm{CH}$ ) nanocomposite. To the best of our knowledge, there was no previous literature report regarding the use of such biopolymer/nanoparticle composite for the removal of $\mathrm{MG}$ dye aqueous media. Thus, the application of nanocomposite for the removal of MG from aqueous solutions was investigated by the influence of different system variables, i.e., solution $\mathrm{pH}$, initial dye concentration, contact time between adsorbate and adsorbent, adsorbent dosage, and temperature, and the adsorption capacity of the nanocomposite for MG has been evaluated as well as the equilibrium isotherms, adsorption kinetics, and thermodynamics studies were also performed.

\section{Materials and Methods}

MG dye, chitin powder, and other reagents used in this work were purchased from ACS Chemicals Pvt. Ltd., Ahmedabad. All the chemicals were of analytical reagent grade and used as such without further purification. Malachite green oxalate [C.I. $=42,000$, CAS number $\left.=123333-61-9, \lambda_{\max }=618 \mathrm{~nm}\right]$ has a chemical formula of $\mathrm{C}_{52} \mathrm{H}_{54} \mathrm{~N}_{4} \mathrm{O}_{12}$ with molecular weight of $927.00 \mathrm{~g} / \mathrm{mol}$. The molecular structures of MG (a) and chitin (b) are illustrated in Fig. 1. Deionized and distilled water were used to prepare all solutions. The MG stock solution was prepared by dissolving an accurately weighed quantity of dye in deionized water and was subsequently diluted to the required concentrations.

\section{Synthesis of Adsorbent (NiO NPs Loaded CH Beads)}

The adsorbent was prepared by the simple precipitation method. In this method, initially, chitin solution was prepared by dissolving chitin powder in $N, N$-dimethylacetamide $/ 5 \%$ lithium chloride $(\mathrm{LiCl})$ solvent system. In this viscous chitin solution, $0.5 \mathrm{~g}$ of nickel oxide nanoparticles, which were synthesized, purified, and characterized by previous reported routes [20,21], was added. The solution was then stirred for $1 \mathrm{~h}$ at $50^{\circ} \mathrm{C}$. After cooling, nickel oxide nanoparticle containing chitin solution was added drop-wise into $100 \mathrm{~mL}$ of nonsolvent coagulant, ethanol, to form spherical uniform beads loaded with $\mathrm{NiO}$ NPs. The final product $(\mathrm{NiO} \mathrm{NPs} / \mathrm{CH})$ nanocomposite was filtered, rinsed several times with doubledistilled water, and dried under vacuum. The dried adsorbents were ground to fine powder for further characterization.

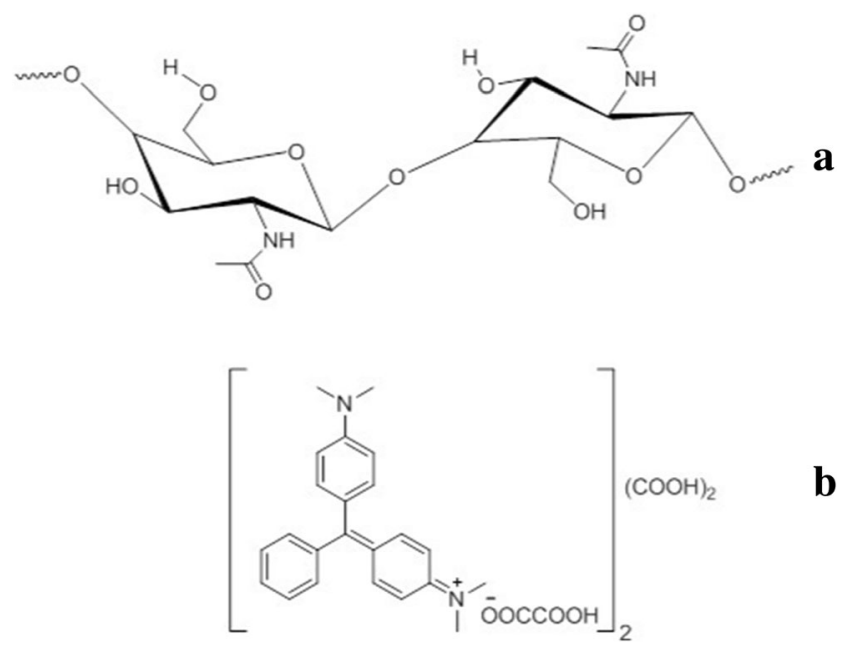

Fig. 1 Molecular structures of chitin (a) and malachite green oxalate (b) 
Figure 2 proposed the synthetic pathway for nanocomposite preparation.

\section{Characterization of Adsorbent}

Transmission electron microscopic (TEM) images of $\mathrm{NiO}$ NPs/CH beads were taken with a Tecnai 20 (Philips, Holland) electron microscope, and the sample was dispersed in aqueous ethanol by ultrasonic stirring in order to analyze the structure and morphology of the samples. To determine the morphological structure and surface characteristic of $\mathrm{NiO}$ $\mathrm{NPs} / \mathrm{CH}$ beads, the samples were coated with gold by electrodeposition under vacuum and examined by scanning electron microscopy (Carl-Zeiss, 40) at an accelerating voltage of $20 \mathrm{kV}$. Fourier transform infrared spectra of the adsorbent were obtained using Shimadzu-8400S FT-IR spectrophotometer. The sample, prepared as $\mathrm{KBr}$ disc, was examined within the range of 400 to $4000 \mathrm{~cm}^{-1}$ to identify the specific functional groups responsible for the adsorption. A double beam UV-Visible spectrophotometer (Evolution 260 BIO UV-Vis. spectrophotometer) was used to determine the unknown concentration of MG solutions. The unknown concentrations of MG solutions were estimated by interpreting the absorbance with standard calibration curve at $618-\mathrm{nm}$ wavelength.

\section{Batch Adsorption Experiments}

The adsorption study was performed by batch experiment to investigate the effect of various parameters on the adsorption of MG. In each batch, $100 \mathrm{~mL}$ dye solution of known concentration $(25-1000 \mathrm{mg} / \mathrm{L})$ was taken in $250-\mathrm{mL}$ standard flask by varying the parameters while keeping the other parameters constant. After regular time interval, the dye solution was centrifuged (Remi Research Centrifuge). The concentration of MG in supernatant solution was determined at characteristic wavelength $\left(\lambda_{\max }=618 \mathrm{~nm}\right)$ by double beam UV-Visible spectrophotometer. The amount of $\mathrm{MG}$ adsorbed $(\mathrm{mg} / \mathrm{g})$ was calculated based on a following mass balance equation.

$\mathrm{q}_{\mathrm{e}}=\frac{\left(\mathrm{C}_{0}-\mathrm{C}_{\mathrm{e}}\right) \mathrm{V}}{\mathrm{W}}$

The removal percentage (R \%) of MG was calculated by the following expression:

$\mathrm{R} \%=\frac{\left(\mathrm{C}_{0}-\mathrm{C}_{\mathrm{e}}\right)}{\mathrm{C}_{0}} \times 100 \%$

where $\mathrm{q}_{\mathrm{e}}(\mathrm{mg} / \mathrm{g})$ is the equilibrium adsorption capacity per gram dry weight of the adsorbent; $\mathrm{C}_{0}(\mathrm{mg} / \mathrm{L})$ is the initial

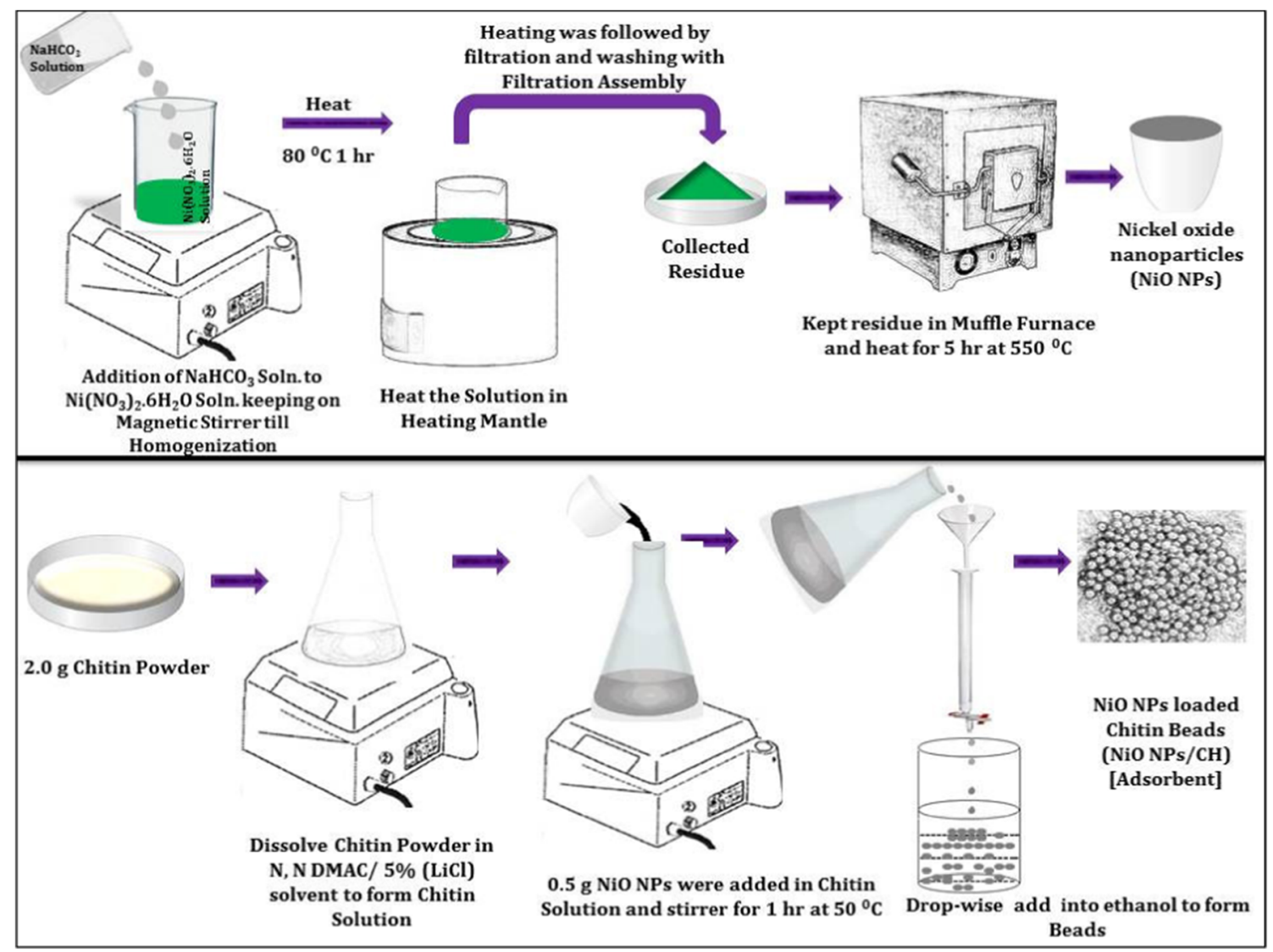

Fig. 2 Synthetic pathway for the preparation of nickel oxide nanoparticles loaded chitin beads 
concentration of MG in the solution; $\mathrm{C}_{\mathrm{e}}(\mathrm{mg} / \mathrm{L})$ is the equilibrium concentration of $\mathrm{MG}$ in the solution; $\mathrm{V}(\mathrm{mL})$ is the volume of the dye solution; and $\mathrm{W}(\mathrm{mg})$ is the dry weight of the nanocomposite.

\section{Desorption and Regeneration Experiments}

In order to make the adsorption process economically more feasible, the desorption efficiency and regeneration potential of adsorbent were studied by repeated desorption/adsorption cycles. Desorption studies were carried out by mixing $100 \mathrm{mg}$ of the $\mathrm{NiO} \mathrm{NPs} / \mathrm{CH}$ beads with $100 \mathrm{~mL}$ of the dye solutions $(100 \mathrm{mg} / \mathrm{L})$. The mixture was shaken for $3 \mathrm{~h}$ at $120 \mathrm{rpm}$ under room temperature $\left(35^{\circ} \mathrm{C}\right)$. The composite was collected and washed several times with distilled water to remove unabsorbed MG. Further, MG-loaded beads were regenerated in $100 \mathrm{~mL}$ of alcohol solution on a rotary shaker at $120 \mathrm{rpm}$; the concentrations of MG in the elutes were determined to investigate the desorption efficiency, and then it was washed with distilled water until a neutral $\mathrm{pH}$ was obtained. The regenerated adsorbent was reused in the next cycle of adsorption experiment.

\section{Results and Discussion}

\section{Transmission Electron Microscope Study}

The size and morphology of $\mathrm{NiO}$ nanoparticles integrated chitin beads have been identified by the transmission electron microscopic (TEM) studies as seen in Fig. 3. The TEM image indicated the presence of dense agglomerates. The nanoparticles have a spherical shape with an average size of $25 \mathrm{~nm}$, and their distribution was not uniform.

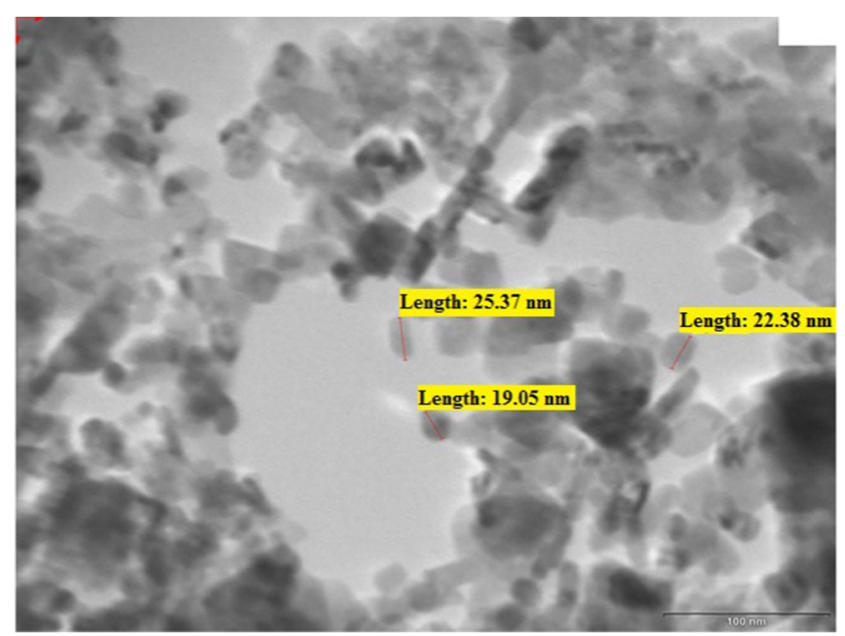

Fig. 3 Transmission electron microscopic (TEM) image of $\mathrm{NiO} \mathrm{NPs} / \mathrm{CH}$

\section{Scanning Electron Microscope Study}

The results of the scanning electron microscopic (SEM) analyses of nanocomposite before (a) and after (b) MG adsorption are illustrated in Fig. 4. The presence of nanoparticles increased the surface area of composite adsorbent, and thus, asymmetrical morphology and high number of aperture can be observed before MG adsorption (Fig. 4a), which becomes even, smooth, flat, and non-porous after dye adsorption as shown in (Fig. 4b). The difference in morphology of adsorbent before and after adsorption of MG can be clearly studied from the SEM analyses.

\section{Fourier Transform Infrared Spectroscopic Study}

FT-IR study was performed to in order to examine and identify the surface groups of the adsorbent responsible for the adsorption of dye.

The FT-IR spectra of adsorbent (nickel oxide nanoparticles loaded chitin beads) before (a) and after (b) dye adsorption are shown in Fig. 5. As shown in Fig. 5a, peaks observed around the 3105.18 to $3444.63 \mathrm{~cm}^{-1}$ were attributed to stretching vibration of hydroxyl groups of adsorbent which were shifted and diminished to lower wave numbers after adsorption of MG (Fig. 5b) and indicated the formation of hydrogen bond between adsorbate and $-\mathrm{OH}$ groups of adsorbent. The peak at $2927.74 \mathrm{~cm}^{-1}$ shown in Fig. 5a was assigned to the $\mathrm{C}-\mathrm{H}$ stretching vibration of polymer backbone. There was a significant decrease and shifting for this peak after MG adsorption which reveals the interaction between adsorbent and dye cation.

Since, during the formation of composite $(\mathrm{NiO} \mathrm{NPs} / \mathrm{CH})$, the interaction occurs between carbonyl oxygen of $\mathrm{NHCOCH}_{3}$ group and metal ion (Ni). Hence, the characteristic peaks for the $\mathrm{N}-\mathrm{H}$ bending vibration of the amide II band and amide III band (located at 1556.45 and $1625.88 \mathrm{~cm}^{-1}$, respectively) reduced and shifted to lower wave numbers. The strong absorption band shown in Fig. $5 \mathrm{a}$ at $439.74 \mathrm{~cm}^{-1}$ was assigned to $\mathrm{Ni}-\mathrm{O}$ stretching vibration. This was shifted from 439.74 to $474.46 \mathrm{~cm}^{-1}$ and diminished due to the interaction of nickel oxide with malachite green dye (Fig. 5b).

\section{Effect of pH}

The effect of initial $\mathrm{pH}$ on the adsorption of MG onto nanocomposite was determined at different $\mathrm{pH}$ values $(2.0-12.0)$ and the results are shown in Fig. 6. The initial $\mathrm{pH}$ of the solution was adjusted by using $0.1 \mathrm{M} \mathrm{HCl}$ and $0.1 \mathrm{M} \mathrm{NaOH}$ solutions after the addition of adsorbent. Other experimental conditions such as initial dye concentration, contact time, temperature, and the amount of adsorbent were fixed at $100 \mathrm{mg} / \mathrm{L}$, $180 \mathrm{~min}, 298 \mathrm{~K}$, and $0.1 \mathrm{~g}$, respectively. 


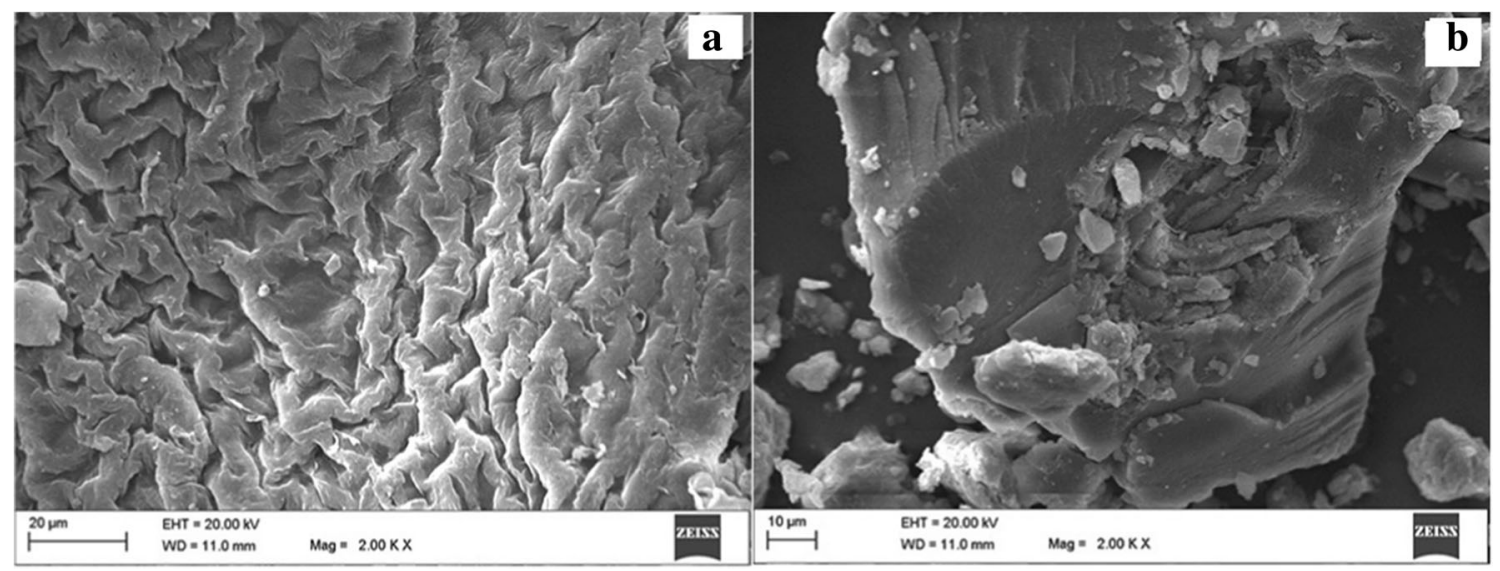

Fig. 4 Scanning electron microscopic (SEM) images of $\mathrm{NiO} \mathrm{NPs/CH}$ beads before (a) and after (b) MG dye adsorption

MG is a basic dye and it exists in aqueous solution in the form of positively charged ions. Being a charged species, its adsorption degree onto adsorbent surface is largely influenced by the surface charge on the adsorbent. At low $\mathrm{pH}$ values, the protonation of the functional groups present on the adsorbent surface easily takes place and thereby restricts the movement
Fig. 5 FT-IR spectra of $\mathrm{NiO}$ $\mathrm{NPs} / \mathrm{CH}$ beads before (a) and after (b) MG dye adsorption
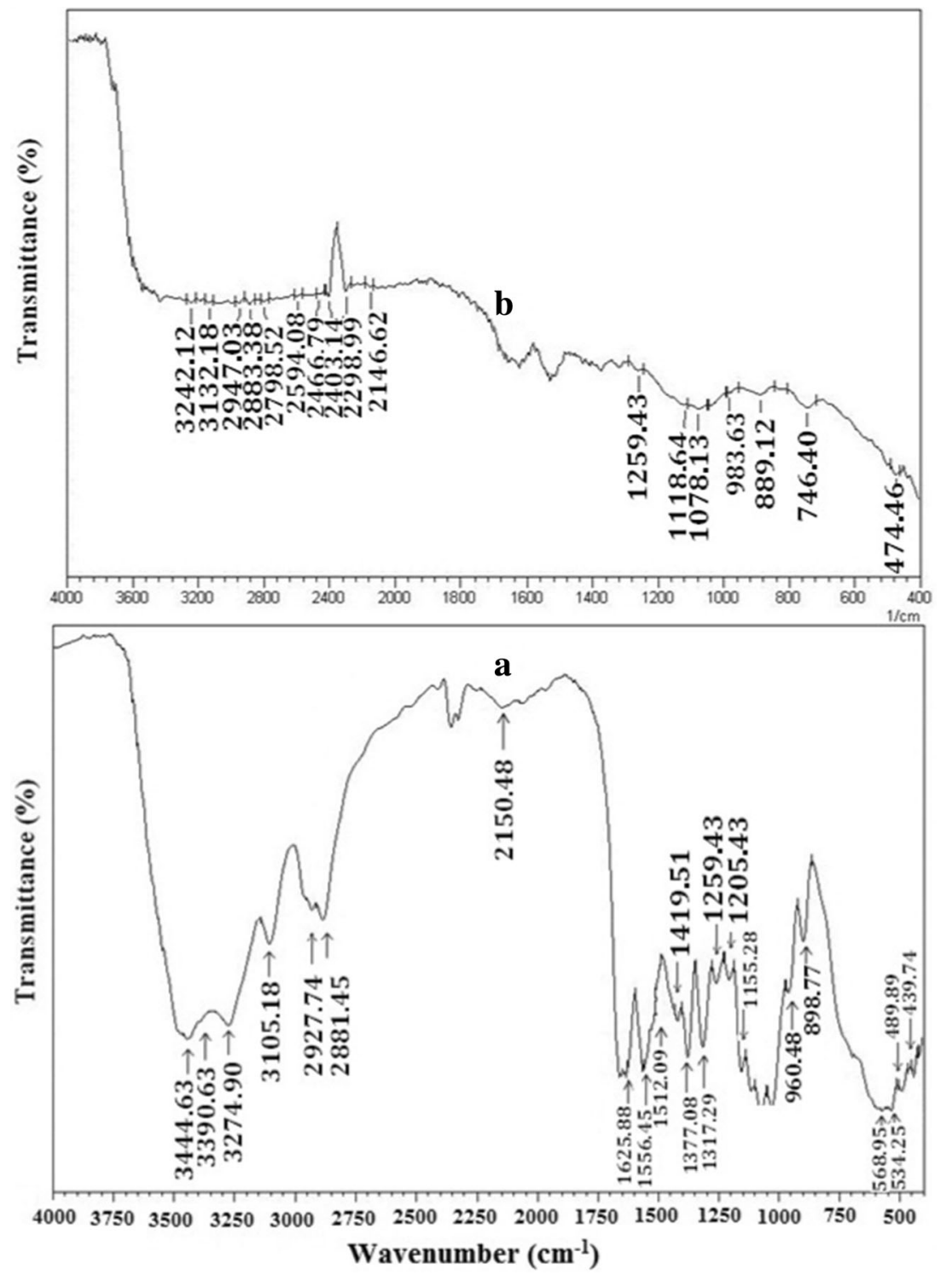


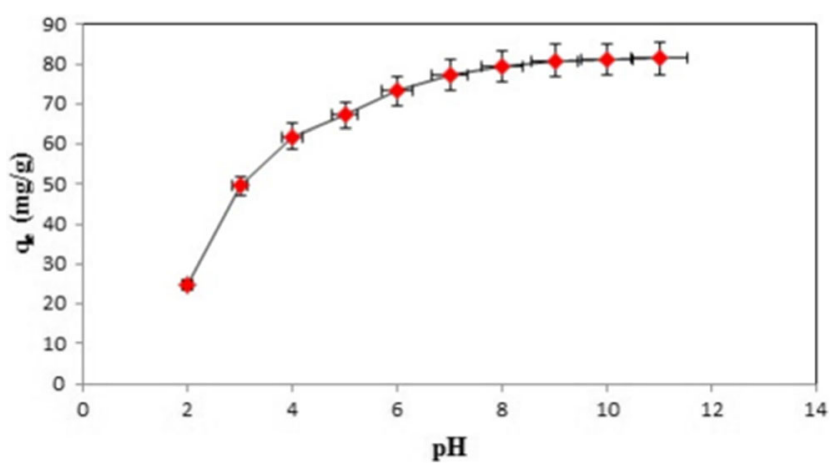

Fig. 6 Effects of $\mathrm{pH}$ on the adsorption of MG by nanocomposite $\left[\mathrm{C}_{0}=100 \mathrm{mg} \mathrm{L}^{-1}\right.$; contact time $=180 \mathrm{~min}$; dosage of adsorbent $=0.1 \mathrm{~g}$; temperature $=298 \mathrm{~K}$; agitation speed $=120 \mathrm{rpm}]$

of positively charged dye cations to the surface of the adsorbent resulting in low adsorption of dye in acidic solution.

With increase in alkalinity of the solution, the functional groups on the adsorbent surface become de-protonated; as a result, the negative charge density on the adsorbent surface increases and facilitates the binding of dye cations. The dye removal capacity can be increased at higher $\mathrm{pH}$ because as the $\mathrm{pH}$ increases, the $\mathrm{H}^{+}$ions get reduced in the solution and may not compete with the dye cations for the appropriate sites on the adsorbent surface. However, at very high $\mathrm{pH}(>10.0)$, there will be no freely available dye cations present in the solution to bound to the adsorbent surface resulting in steady adsorption condition.

The structural stability and color intensity of MG dye are affected by the $\mathrm{pH}$ of the solution because it gets protonated in the acidic medium and de-protonated in the alkaline medium. According to [22], the color of MG is stable in the initial $\mathrm{pH}$ range 3.0-7.0, and the color reduction increases as initial $\mathrm{pH}$ increases from 7.0 to 11.0. Looking upon this nature of the dye and the above result of the effects of $\mathrm{pH}$, further studies were then carried out with dye solutions at $\mathrm{pH}$ value 7.0.

\section{Effect of Initial Dye Concentration and Contact Time}

The effects of different initial dye concentrations and contact time on the adsorptive removal of MG by nanocomposite at the $\mathrm{pH}$ value of 7.0 are shown in Fig. 7. From the figure, it can be seen that with increasing initial dye concentration from 25 to $1000 \mathrm{mg} / \mathrm{L}$, the amount of dye adsorption was also increased from 34.02 to $106.47 \mathrm{mg} / \mathrm{g}$. This increase in dye adsorption was found due to high driving force for mass transfer at enhanced dye concentration, and the resistance to the uptake of MG from the solution decreases with the increase in dye concentration. When the surface active sites of adsorbents are covered fully, the extent of adsorption reaches a limit resulting in saturated adsorption.

Figure 7 also represents that the adsorption of $M G$ is fast at the initial stage of contact with the adsorbent, and then, it becomes slow near the equilibrium. During the initial contact

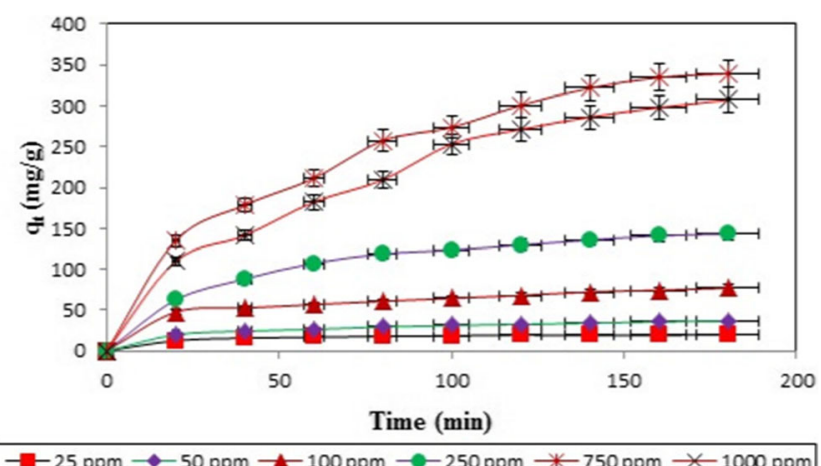

Fig. 7 Effects of initial dye concentrations and contact time on the adsorption of $\mathrm{MG}$ by nanocomposite $[\mathrm{pH}=7.0$; dosage of adsorbent $=0.1 \mathrm{~g}$; agitation speed $=120 \mathrm{rpm}]$

time, a large number of vacant surface sites are available for adsorption, and at maximum contact time, aggregation of dye molecules makes it difficult to diffuse deeper into the adsorbent structure at highest energy sites. From the graph, it can be seen that after 150-min contact, a steady-state approximation was achieved and a quasi-equilibrium situation was accepted. Based on the above results, 180-min contact time was fixed as equilibrium time throughout the adsorption study.

\section{Effect of Adsorbent Dosage}

The percentage of MG adsorption with varying amount of adsorbent is presented in Fig. 8a. Generally, with increasing adsorbent dosage, the percentage removal of adsorbate also
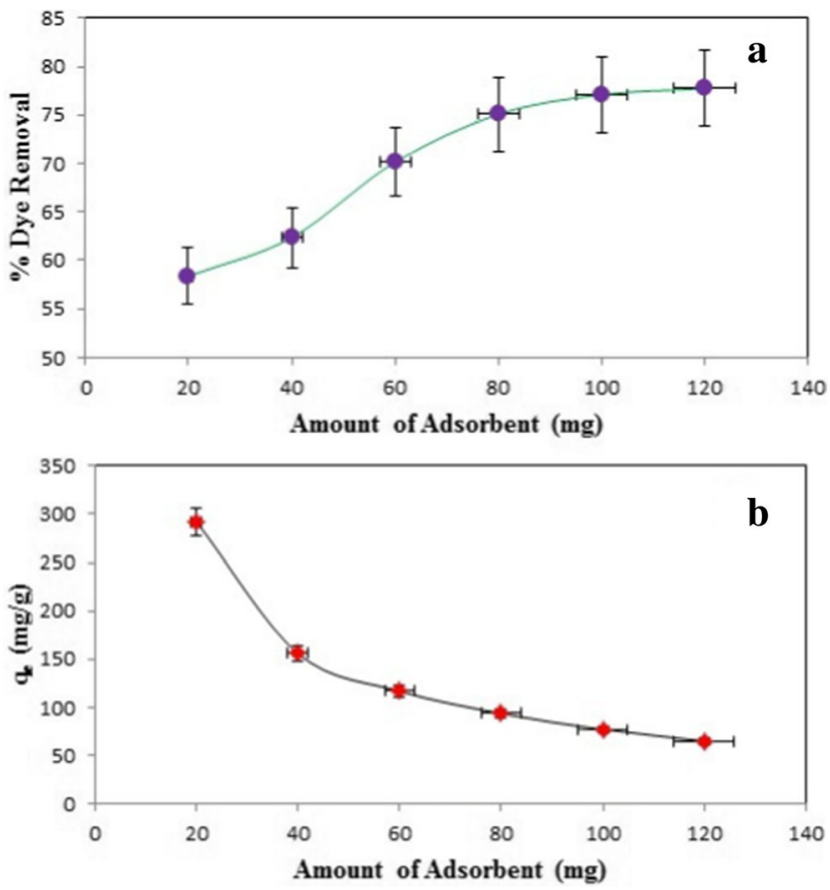

Fig. 8 Effects of amount of adsorbent on the percentage removal (a) and the adsorption capacity (b) of MG by $\mathrm{NiO} \mathrm{NPs} / \mathrm{CH}\left[\mathrm{C}_{0}=100 \mathrm{mg} / \mathrm{L}\right.$; $\mathrm{pH}=7.0$; contact time $=180 \mathrm{~min}$; agitation speed $=120 \mathrm{rpm}]$ 
increases. It can be seen from the figure that the $\%$ dye removal increased from 58.37 to $77.73 \%$ as the dose increased from 0.002 to $0.120 \mathrm{~g}$. Initially, the higher uptake of dye can be attributed to the availability of larger surface area and more number of adsorption sites. There was no significant increase in the \% removal of dye can be observed for a dose greater than $0.10 \mathrm{~g}$ of nanocomposite in $100 \mathrm{~mL}$ of $\mathrm{MG}$ solution. Thus, the optimum dose adopted is $0.1 \mathrm{~g} / 100 \mathrm{~mL}$. The amount of $\mathrm{MG}$ adsorbed $\left(\mathrm{q}_{\mathrm{e}}\right)$ decreased from 291.83 to $64.77 \mathrm{mg} / \mathrm{g}$, when the adsorbent dosage was increased from 0.002 to $0.120 \mathrm{~g} / 100 \mathrm{~mL}$ (Fig. 8b). The decrease in amount of $\mathrm{MG}$ adsorbed onto adsorbents $\mathrm{q}_{\mathrm{e}}(\mathrm{mg} / \mathrm{g})$ with increasing adsorbent dosage was due to a split in the flux or the concentration gradient between MG concentration in the solution and on the surface of the adsorbent.

\section{Effect of Temperature}

The adsorption studies were carried out at three different temperatures $\left(25,35\right.$, and $\left.45^{\circ} \mathrm{C}\right)$, and the results of these experiments are shown in Fig. 9. It was observed that as the temperature increased, the adsorption capacity decreases, which indicated that the process was exothermic in nature. With increasing temperature, the mobility of the larger dye ions also increases, which leads to a decrease in its adsorption. Similar results have been reported for the biosorption of Basic Green 4 dye by using Ananas comosus (pineapple) leaf powder from an aqueous solution [23].

\section{Equilibrium Adsorption Isotherms}

Adsorption isotherms describe how the adsorbate interacts with adsorbent and provide comprehensive understanding about the nature of the interaction. Isotherms help to provide information about the optimum use of adsorbents. So, in order to optimize the design of an adsorption system to remove dye from solutions, it is essential to establish the most appropriate correlation for the equilibrium curve [24]. The most widely used isotherm models for solid-liquid adsorption are the
Langmuir and Freundlich. The equilibrium data were analyzed using these two isotherm models.

The Langmuir isotherm predicts the formation of a monolayer of the adsorbate on the homogenous adsorbent surface. It assumes that each adsorbate molecule is located at specific homogenous sites within the adsorbent and thus does not consider surface heterogeneity of the adsorbent. The linear form of the Langmuir adsorption isotherm [25] is represented as follows:

$\frac{C_{e}}{q_{e}}=\frac{1}{K_{L}}+\frac{a_{L}}{K_{L}} \cdot C_{e}$

where $C_{e}(\mathrm{mg} / \mathrm{L})$ is the equilibrium concentration of the $\mathrm{MG}$ in the solution. $q_{e}(\mathrm{mg} / \mathrm{g})$ is the equilibrium adsorption capacity per gram dry weight of the adsorbent corresponding to complete coverage of the adsorptive sites. $a_{L}(\mathrm{~L} / \mathrm{mg})$ and $K_{L}$ $(\mathrm{L} / \mathrm{g})$ are the Langmuir isotherm constants. The parameters of the Langmuir equation were calculated and given in Table 1.

The maximum adsorption capacities of MG by nanocomposite at 25,35 , and $45^{\circ} \mathrm{C}$ were $370.37,357.14$, and $344.83 \mathrm{mg} / \mathrm{g}$, respectively. To confirm the favorability of the adsorption process, the dimensionless "separation factor" or "equilibrium parameter" $\left(\mathrm{R}_{\mathrm{L}}\right)$ expressed by Eq. (4) was used:

$R_{L}=\frac{1}{\left(1+a_{L} \cdot C_{0}\right)}$.

The $R_{L}$ value indicates whether the adsorption is unfavorable $\left(R_{L}>1\right)$, linear $\left(R_{L}=1\right)$, favorable $\left(0<R_{L}<1\right)$, or irreversible $\left(R_{L}=0\right)$ [26]. The $R_{L}$ values, listed in Table 1 , were between 0 and 1 which depicts that $\mathrm{NiO} \mathrm{NPs} / \mathrm{CH}$ is a favorable adsorbent for MG.

Freundlich adsorption isotherm [27] defines the adsorption onto the adsorbent with heterogeneous surface. The linear form of Freundlich isotherm model is as follows:

$\log \mathrm{q}_{\mathrm{e}}=\log \mathrm{K}_{\mathrm{F}}+\frac{1}{\mathrm{n}} \log \mathrm{C}_{\mathrm{e}}$

where $\mathrm{K}_{\mathrm{F}}(\mathrm{mg} / \mathrm{g})$ is the Freundlich adsorption isotherm constant, relating to the extent of adsorption and $n(\mathrm{~g} / \mathrm{L})$ is the
Fig. 9 Effects of temperature for the adsorption of $\mathrm{MG}$ onto nanocomposite $[\mathrm{pH}=7.0$; contact time $=180 \mathrm{~min}$; agitation speed $=120 \mathrm{rpm}]$. Inset of Fig. 9 Van't Hoff plot of $\ln \mathrm{K}_{\mathrm{c}}$ vs. 1/T for the adsorption of $\mathrm{MG}$ onto nanocomposite $\left[\mathrm{C}_{0}=100 \mathrm{mg} \mathrm{L}^{-1}\right]$

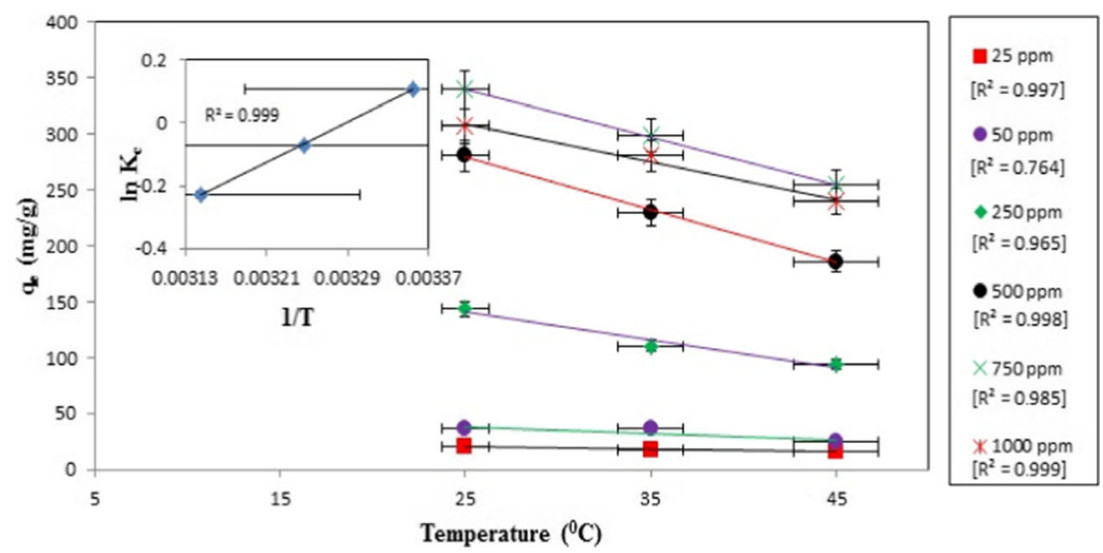


Table 1 Constants for equilibrium isotherm models with error analysis values for the adsorption of malachite green by nanocomposite $(\mathrm{NiO} \mathrm{NPs} / \mathrm{CH}$ beads) and chitin $(\mathrm{CH})$ beads

\begin{tabular}{|c|c|c|c|c|c|c|c|}
\hline & \multirow[t]{2}{*}{ Isotherm parameters } & \multicolumn{3}{|c|}{$\mathrm{NiO} \mathrm{NPs} / \mathrm{CH}$ beads } & \multicolumn{3}{|l|}{$\mathrm{CH}$ beads } \\
\hline & & $298 \mathrm{~K}$ & $308 \mathrm{~K}$ & $318 \mathrm{~K}$ & $298 \mathrm{~K}$ & $308 \mathrm{~K}$ & $318 \mathrm{~K}$ \\
\hline \multirow[t]{5}{*}{ Langmuir isotherm } & $\mathrm{q}_{\mathrm{m}}(\mathrm{mg} / \mathrm{g})$ & 370.37 & 357.14 & 344.83 & 142.86 & 138.89 & 129.87 \\
\hline & $\mathrm{a}_{\mathrm{L}}(\mathrm{L} / \mathrm{mg})$ & 0.0096 & 0.0058 & 0.0035 & 0.0022 & 0.0019 & 0.0017 \\
\hline & $R_{\mathrm{L}}$ & $0.806-0.094$ & $0.874-0.147$ & $0.921-0.225$ & $0.948-0.313$ & $0.955-0.345$ & $0.958-0.365$ \\
\hline & $R^{2}$ & 0.970 & 0.932 & 0.911 & 0.889 & 0.807 & 0.762 \\
\hline & $\chi^{2}$ & 25.82 & 31.36 & 16.64 & 4.598 & 6.165 & 7.354 \\
\hline \multirow[t]{5}{*}{ Freundlich isotherm } & $\mathrm{K}_{\mathrm{F}}(\mathrm{L} / \mathrm{g})$ & 9.84 & 6.24 & 3.35 & 1.202 & 1.021 & 1.014 \\
\hline & $1 / n$ & 0.552 & 0.610 & 0.672 & 1.541 & 1.567 & 1.565 \\
\hline & $n$ & 1.812 & 1.639 & 1.488 & 0.649 & 0.638 & 0.639 \\
\hline & $R^{2}$ & 0.939 & 0.976 & 0.979 & 0.979 & 0.934 & 0.934 \\
\hline & $\chi^{2}$ & 66.49 & 30.75 & 22.08 & 2.576 & 6.725 & 6.67 \\
\hline
\end{tabular}

Freundlich exponent. The values of $\mathrm{K}_{\mathrm{F}}$ and $\frac{1}{\mathrm{n}}$ were calculated from the slope and intercept of the plot of $\log \mathrm{q}_{\mathrm{e}} \mathrm{vs} \cdot \log \mathrm{C}_{\mathrm{e}}$ and listed in Table 1. From the results, it can be seen that the values for $\frac{1}{n}$ were below 1 at different temperatures, which indicated that a normal Langmuir isotherm adsorption was followed for the adsorption of $\mathrm{MG}$ onto $\mathrm{NiO} \mathrm{NPs} / \mathrm{CH}$ beads.

The graphs for the Langmuir (a) and Freundlich (b) adsorption isotherm models (shown in Fig. 10) have been plotted to
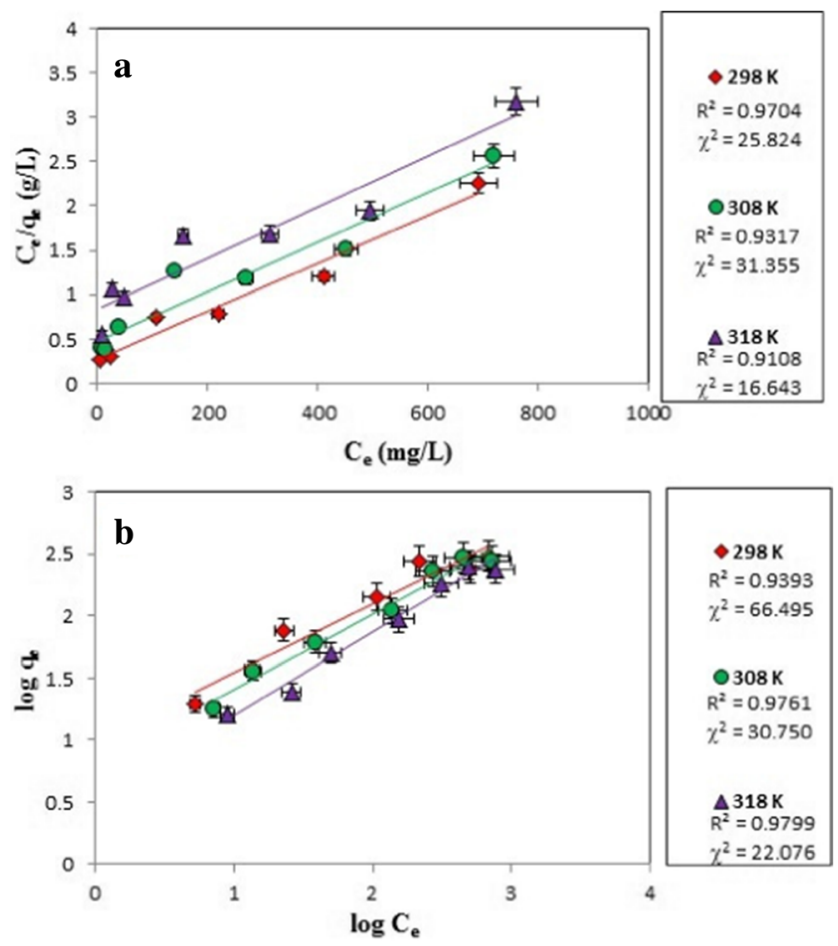

Fig. 10 Langmuir (a) and Freundlich (b) isotherm plots for the adsorption of $\mathrm{MG}$ onto $\mathrm{NiO} \mathrm{NPs} / \mathrm{CH}[\mathrm{pH}=7.0$; contact time $=180 \mathrm{~min}$; dosage of adsorbent $=0.1 \mathrm{~g}$; agitation speed $=120 \mathrm{rpm}$ ] obtain their different constants, which are given in Table 1. Although the values of correlation coefficient were less for Langmuir isotherm compare to the Freundlich isotherm, from the values of non-linear chi-square statistic test, it can be concluded that the Langmuir isotherm was the best fitted adsorption isotherm model for the MG dye adsorption onto $\mathrm{NiO}$ $\mathrm{NPs} / \mathrm{CH}$ beads. On the other hand, for the adsorption of MG onto $\mathrm{CH}$ beads, the adsorption process followed the Freundlich adsorption isotherm model.

\section{Error Analysis}

For the evaluation of the best fitting isotherm equation to the experimental equilibrium data, an error function has to be performed. In this study, linear coefficient of determination $\left(R^{2}\right)$ and a non-linear chi-square test $\left(\chi^{2}\right)$ were performed for both the single component isotherms. The chi-square test statistics refers to the sum of the squares of the differences between the experimental data and the data obtained by calculating from isotherm models, with each squared difference divided by the corresponding data obtained by calculating from models. The mathematical equation can be represented as follows:

$\chi^{2}=\sum \frac{\left(q_{e(\exp )}-q_{e(c a l)}\right)^{2}}{q_{e(c a l)}}$

where $q_{e(\exp )}(\mathrm{mg} / \mathrm{g})$ is the experimental data of the equilibrium capacity; and $q_{e(c a l)}(\mathrm{mg} / \mathrm{g})$ is the equilibrium capacity obtained by calculating from the model. If data from the model are similar to the experimental data, $\chi^{2}$ will be a smaller number, and if they differ, $\chi^{2}$ will be a bigger number. Therefore, it is necessary to analyze the data using the non- 
linear chi-square test to confirm the suitable isotherm for this adsorption system [28]. The results of the linear coefficient of determination $\left(R^{2}\right)$ and a non-linear chi-square test $\left(\chi^{2}\right)$ for both the adsorption isotherms indicated that the adsorption process of MG dye onto nanocomposite was homogenous in nature, and Langmuir isotherm model appeared to be the best fitted model. Whereas the adsorption process of MG dye onto only chitin beads was heterogeneous in nature, and Freundlich isotherm model appeared to be the best fitting model.

\section{Adsorption Kinetics}

The kinetics study is helpful to select the optimum operating conditions for the full-scale batch process as well as it also provides valuable insights into the reaction pathways and in turn controls the residence time of adsorbate uptake at the solid-solution interface [29]. To investigate the adsorption kinetics of MG onto the nanocomposite, the linear forms of pseudo-first-order, pseudo-second-order, and intraparticle diffusion model were used.

The linear equations for the applied models were as follows:

Pseudo-first-order model:

$\log \left(q_{e}-q_{t}\right)=\log q_{e}-\frac{k_{1}}{2.303} t$.

Pseudo-second-order model:

$\frac{t}{q_{t}}=\frac{1}{k_{2} q_{e}{ }^{2}}+\frac{\mathrm{t}}{q_{e}}$.

Intraparticle diffusion model:

$q_{t}=K_{i d} t^{1 / 2}+I$

where $q_{e}$ and $q_{t}(\mathrm{mg} / \mathrm{g})$ are the amounts of dye adsorbed on adsorbent at equilibrium and at time $t$, respectively, and $\mathrm{k}_{1}$ $\left(\mathrm{min}^{-1}\right)$ and $\mathrm{k}_{2}(\mathrm{~g} / \mathrm{mg} \mathrm{min})$ are the rate constants of pseudofirst-order and pseudo-second-order kinetic models. $K_{i d}$ is the intraparticle diffusion rate constant $\left(\mathrm{mg} / \mathrm{g} \mathrm{min}{ }^{1 / 2}\right)$ and $I(\mathrm{mg} / \mathrm{g})$ is the intercept.

The straight line plots for the pseudo-first-order (a) and pseudo-second-order (b) models (shown in Fig. 11, respectively) have been represented to obtain the rate parameters which are given in Table 2. From the resulting data, it can be seen that the $R^{2}$ value of the pseudo-second-order equation is higher than that of the pseudo-first-order equation, indicating that experimental kinetic data for MG adsorption followed the pseudo-second-order rate model better than the other one. As shown in Table 2, the values of the rate constant $\mathrm{k}_{2}$ decrease with increasing initial MG dye concentration because higher dye concentration corresponds to higher surface loading which decreases the diffusion efficiency.
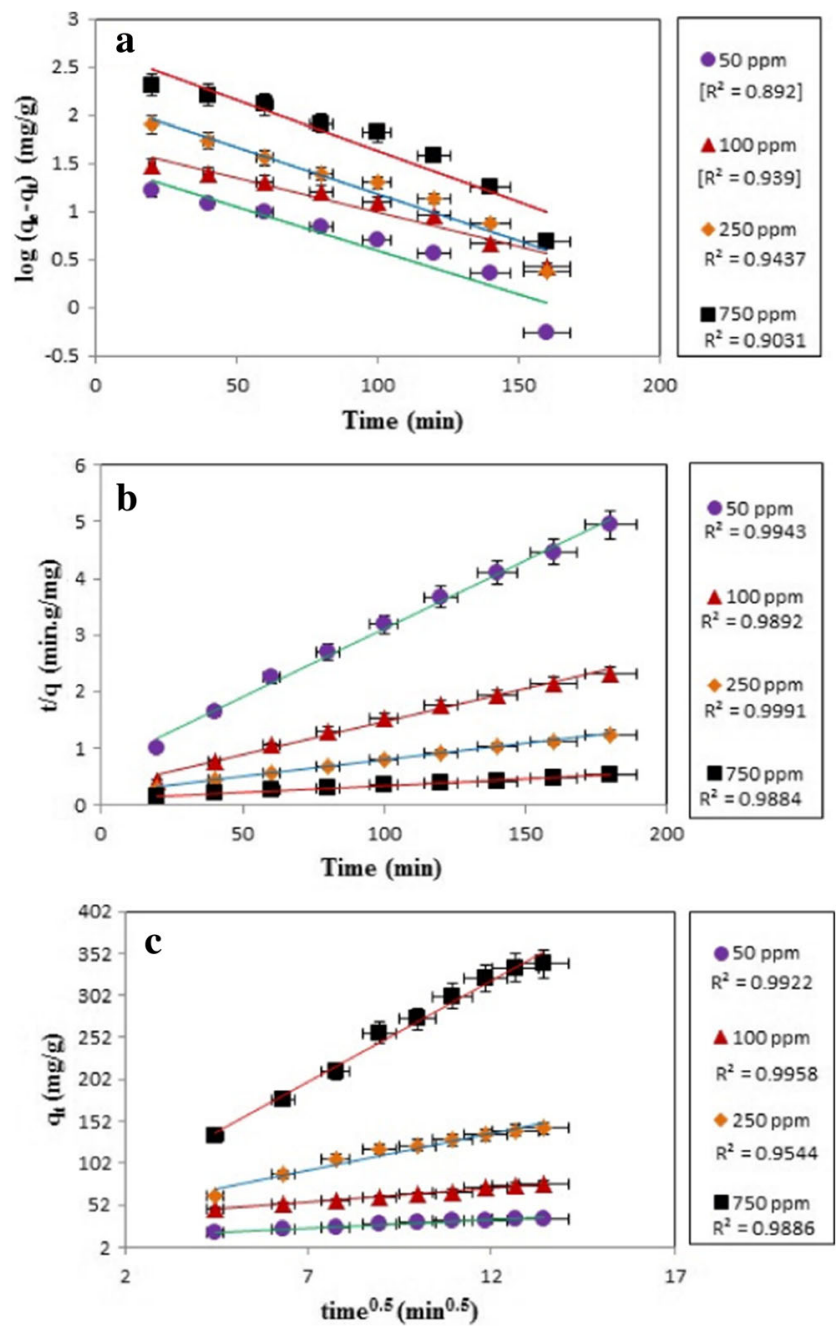

Fig. 11 a Pseudo-first-order, b pseudo-second-order, and $\mathbf{c}$ intraparticle diffusion models for the adsorption of $\mathrm{MG}[\mathrm{pH}=7.0$; dosage of adsorbent $=0.1 \mathrm{~g}$; temperature $=298 \mathrm{~K}$; agitation speed $=120 \mathrm{rpm}]$

The adsorbate species are most probably transported from the bulk of the solution into the solid phase through intraparticle diffusion/transport process, which is often the rate-limiting step in many adsorption processes. The possibility of intraparticle diffusion was explored by using the intraparticle diffusion model, which is commonly expressed by Eq. (7).

The value of intercept $(I)$, provides information about the thickness of the boundary layer, in the present study ranging from 0.53 to 4.638 indicated that the boundary layer effect was not so much efficient for the adsorption of MG onto nanocomposite. In Fig. $11 \mathrm{c}$, the plot of $t^{1 / 2}$ vs. $\mathrm{q}_{\mathrm{t}}$ was linear in nature indicated that the intraparticle diffusion was involved in the adsorption process. It can also be seen that the linear portions of curves do not pass through the origin which indicates that the intraparticle diffusion is not the sole rate controlling step for the adsorption mechanism of MG onto nanocomposite. From the above results, it may be concluded that surface adsorption and intraparticle diffusion were concurrently operating during the adsorbate and adsorbent interactions [30]. 
Table 2 Kinetic parameters for the removal of malachite green by NiO NPs/CH beads

\begin{tabular}{|c|c|c|c|c|c|c|c|c|}
\hline & Kinetic parameters $(318 \mathrm{~K})$ & $25 \mathrm{mg} / \mathrm{L}$ & $50 \mathrm{mg} / \mathrm{L}$ & $100 \mathrm{mg} / \mathrm{L}$ & $250 \mathrm{mg} / \mathrm{L}$ & $500 \mathrm{mg} / \mathrm{L}$ & $750 \mathrm{mg} / \mathrm{L}$ & $1000 \mathrm{mg} / \mathrm{L}$ \\
\hline \multirow[t]{4}{*}{ Pseudo-first-order model } & $\mathrm{q}_{\mathrm{e}(\exp )}(\mathrm{mg} / \mathrm{g})$ & 16.05 & 24.14 & 50.499 & 93.81 & 185.97 & 254.86 & 239.31 \\
\hline & $\mathrm{k}_{1}(\mathrm{~L} / \mathrm{min})$ & 0.0184 & 0.0237 & 0.0281 & 0.0205 & 0.0223 & 0.0179 & 0.0175 \\
\hline & $\mathrm{q}_{\mathrm{e}}(\mathrm{mg} / \mathrm{g})$ & 20.003 & 32.569 & 92.683 & 101.11 & 262.301 & 266.69 & 265.644 \\
\hline & $R^{2}$ & 0.827 & 0.907 & 0.887 & 0.957 & 0.924 & 0.959 & 0.982 \\
\hline \multirow[t]{3}{*}{ Pseudo-second-order model } & $\mathrm{k}_{2}(\mathrm{~g} / \mathrm{mg} \min )$ & 0.00062 & 0.00046 & 0.00022 & 0.0001 & 0.000054 & 0.000049 & 0.000039 \\
\hline & $\mathrm{q}_{\mathrm{e}}(\mathrm{mg} / \mathrm{g})$ & 21.645 & 33.223 & 69.444 & 135.135 & 256.51 & 333.33 & 333.33 \\
\hline & $\mathrm{R}^{2}$ & 0.938 & 0.985 & 0.949 & 0.938 & 0.974 & 0.984 & 0.977 \\
\hline \multirow[t]{3}{*}{ Intraparticle diffusion model } & $\mathrm{K}_{\mathrm{id}}\left(\mathrm{mg} / \mathrm{g} \min ^{1 / 2}\right)$ & 1.14 & 1.83 & 3.676 & 7.075 & 13.99 & 18 & 18.11 \\
\hline & I (mg/g) & 0.536 & 1.035 & 3.173 & 4.638 & 4.132 & 18.76 & 0.983 \\
\hline & $R^{2}$ & 0.978 & 0.948 & 0.965 & 0.894 & 0.989 & 0.975 & 0.989 \\
\hline
\end{tabular}

\section{Thermodynamic Study}

The thermodynamic parameters such as change in Gibbs free energy $\left(\Delta \mathrm{G}^{\circ}\right)$, change in enthalpy $\left(\Delta \mathrm{H}^{\circ}\right)$, and change in entropy $\left(\Delta \mathrm{S}^{\circ}\right)$ were also studied for better understanding of the effect of temperature on the adsorption process.

The Gibbs free energy of adsorption $\Delta G^{o}$ is calculated from the following equation:

$\Delta G^{o}=-R T \ln K_{C}$

where $\mathrm{K}_{\mathrm{C}}$ is the adsorption equilibrium constant. The value of $\mathrm{K}_{\mathrm{C}}$ is calculated from the following equation:

$\mathrm{K}_{\mathrm{c}}=\frac{\mathrm{C}_{a e}}{\mathrm{C}_{\mathrm{e}}}$

where $C_{a e}$ is the equilibrium dye concentration on the adsorbent $(\mathrm{mg} / \mathrm{L})$, and $\mathrm{C}_{\mathrm{e}}$ is the equilibrium dye concentration in solution $(\mathrm{mg} / \mathrm{L})$.

Standard enthalpy and standard entropy of adsorption can be estimated from Van't Hoff equation:

$\ln \mathrm{K}_{\mathrm{c}}=-\frac{\Delta \mathrm{H}^{\mathrm{o}}}{\mathrm{RT}}+\frac{\Delta \mathrm{S}^{\mathrm{o}}}{\mathrm{R}}$.

The values of $\Delta \mathrm{H}^{\mathrm{o}}$ and $\Delta S^{o}$ were calculated from the slope and intercept of Van't Hoff plot (presented in the inset curve of Fig. 9) of $\ln K_{c}$ vs. $1 / T$ and are given in Table 3.

Thermodynamic parameters are listed in Table 3 . The negative values of $\Delta \mathrm{G}^{\circ}$ for $\mathrm{NiO} \mathrm{NPs} / \mathrm{CH}$ beads demonstrated a spontaneous and favorable adsorption process. The higher negative value reflects more energetic favorable adsorption. On the contrary, the positive value of $\Delta \mathrm{G}^{\circ}$ for $\mathrm{CH}$ beads indicated that the adsorption of $\mathrm{MG}$ dye onto $\mathrm{CH}$ beads was a non-spontaneous process. The values of $\Delta \mathrm{H}^{\circ}$ were negative for adsorption of MG onto $\mathrm{NiO} \mathrm{NPs} / \mathrm{CH}$, and the absolute values were lower than $40 \mathrm{~kJ} / \mathrm{mol}$. This indicated that the adsorption was an exothermic physical process. The negative values of $\Delta \mathrm{S}^{\circ}$ obtained reveal that the internal structure of the adsorbents does not go through any significant change as well as a slight decrease in randomness at the solid-solution interface with increasing temperature during the adsorption of the dye [31].

\section{Desorption and Regeneration Studies}

To evaluate the possibility of regeneration of composite adsorbent, desorption experiments have been performed. The cycles of adsorption/desorption experiments were carried out up to three times. After four cycles, the adsorption capacities of MG dye on adsorbent decrease from 61.59 to $50.32 \%$. This behavior indicates that the adsorbent can be reused successfully four times for the MG adsorption from aqueous solution.

\section{Comparison with Other Adsorbents for the Removal of MG}

Table 4 represents the comparison of various composite and nanocomposite adsorbents previously used for the removal of MG with the present study. From the table, it can be seen that although the present adsorbent showed very less adsorption capacity $(370.37 \mathrm{mg} / \mathrm{g})$ compared to other materials, but still it has the following advantages over other adsorbents:

(i) The preparation of present nanocomposite $(\mathrm{NiO} \mathrm{NPs} / \mathrm{CH})$ is very simple, easy, and facile process which required fewer chemicals.

(ii) Chitin (marine byproduct) has been utilized so its disposal problem can be overcome. In addition, due to the biodegradable nature, it would not create the secondary pollution. 
Table 3 The obtained thermodynamic parameters for the adsorption of malachite green by nanocomposite $(\mathrm{NiO} \mathrm{NPs} / \mathrm{CH}$ beads) and chitin beads

\begin{tabular}{|c|c|c|c|c|c|c|c|}
\hline \multicolumn{8}{|c|}{$\mathrm{NiO} \mathrm{NPs} / \mathrm{CH}$ beads } \\
\hline Sr. no. & $\mathrm{C}_{0}(\mathrm{mg} / \mathrm{L})$ & $\mathrm{K}_{\mathrm{c}}$ & $1 / \mathrm{T}\left(\mathrm{K}^{-1}\right)$ & $\Delta \mathrm{G}^{\circ}(\mathrm{kJ} / \mathrm{mol})$ & \multirow{4}{*}{$\begin{array}{l}\Delta \mathrm{S}^{\circ}(\mathrm{kJ} / \mathrm{mol} / \mathrm{K}) \\
-0.086\end{array}$} & \multirow{4}{*}{$\begin{array}{l}\Delta \mathrm{H}^{\circ}(\mathrm{kJ} / \mathrm{mol}) \\
-28.824\end{array}$} & \multirow{3}{*}{$\begin{array}{l}R^{2} \\
0.995\end{array}$} \\
\hline 1. & 25 & 3.721 & 0.00336 & -3.256 & & & \\
\hline 2. & 25 & 2.438 & 0.00325 & -2.283 & & & \\
\hline 3. & 25 & 1.792 & 0.00314 & -1.543 & & & \\
\hline \multicolumn{8}{|c|}{$\mathrm{CH}$ beads } \\
\hline Sr. no. & $\mathrm{C}_{0}(\mathrm{mg} / \mathrm{L})$ & $\mathrm{K}_{\mathrm{c}}$ & $1 / \mathrm{T}\left(\mathrm{K}^{-1}\right)$ & $\Delta \mathrm{G}^{\circ}(\mathrm{kJ} / \mathrm{mol})$ & $\Delta \mathrm{S}^{\circ}(\mathrm{kJ} / \mathrm{mol} / \mathrm{K})$ & $\Delta \mathrm{H}^{\circ}(\mathrm{kJ} / \mathrm{mol})$ & $R^{2}$ \\
\hline 1. & 25 & 0.559 & 0.00336 & 1.443 & \multirow{3}{*}{-0.007} & \multirow[t]{3}{*}{-0.633} & \multirow[t]{3}{*}{0.986} \\
\hline 2. & 25 & 0.553 & 0.00325 & 1.516 & & & \\
\hline 3. & 25 & 0.549 & 0.00314 & 1.582 & & & \\
\hline
\end{tabular}

(iii) As stated by Ali (2010) [32], separation and aggregation of nanomaterials is hurdle to their use in actual system. Thus, to overcome this problem, they suggested for the new bio-nanocomposite as green adsorbents. Hence, by using this bio-nanocomposite, we can easily regenerate/ reutilize the spent adsorbent in a simple manner.

Table 4 Comparison of maximum adsorption capacity of various composite and nanocomposite adsorbents towards malachite green dye

\begin{tabular}{|c|c|c|c|c|c|c|c|c|c|}
\hline Sr. no. & Adsorbents & $\begin{array}{l}\mathrm{q}_{\max } \\
(\mathrm{mg} / \mathrm{g})\end{array}$ & $\begin{array}{l}\text { Isotherm } \\
\text { study }\end{array}$ & Kinetics study & $\begin{array}{l}\text { Thermodynamic } \\
\text { study }\end{array}$ & $\mathrm{pH}$ & $\begin{array}{l}\text { Equilibrium } \\
\text { time (min) }\end{array}$ & $\begin{array}{l}\text { Dosage of } \\
\text { adsorbent }\end{array}$ & References \\
\hline 1. & $\begin{array}{l}\text { Magnetic } \beta \text {-cyclodextrin- } \\
\text { graphene oxide } \\
\text { nanocomposites }\left(\mathrm{Fe}_{3} \mathrm{O}_{4} / \beta \text { - }\right. \\
\mathrm{CD} / \mathrm{GO})\end{array}$ & 990.10 & Langmuir & $\begin{array}{l}\text { Pseudo-second- } \\
\text { order }\end{array}$ & Endothermic & 7.0 & $120 \mathrm{~min}$ & - & {$[33]$} \\
\hline 2. & $\begin{array}{l}\text { Kappa-carrageenan-g- } \\
\text { polyacrylic acid/ } / \mathrm{TiO}_{2}-\mathrm{NH}_{2} \\
\text { hydrogel nanocomposite }\end{array}$ & 666.66 & Langmuir & $\begin{array}{l}\text { Pseudo-second- } \\
\text { order }\end{array}$ & Exothermic & 7.0 & $180 \mathrm{~min}$ & $0.05 \mathrm{~g} / 200 \mathrm{~mL}$ & {$[34]$} \\
\hline 3. & $\begin{array}{l}\text { Poly(vinyl alcohol) and chitosan } \\
\text { (PVA/CS composite) }\end{array}$ & 380.65 & Freundlich & $\begin{array}{l}\text { Pseudo-second- } \\
\text { order }\end{array}$ & Endothermic & 6.0 & $540 \mathrm{~min}$ & $0.1 \mathrm{~g} / 50 \mathrm{~mL}$ & {$[35]$} \\
\hline 4. & $\begin{array}{l}\text { Alginate/poly aspartate } \\
\text { composite hydrogel beads }\end{array}$ & $300-350$ & - & - & - & - & $3.0 \mathrm{~h}$ & $0.1 \mathrm{~g} / 50 \mathrm{~mL}$ & {$[36]$} \\
\hline 5. & $\begin{array}{l}\text { Polyacrylic acid-nanoclay } \\
\text { nanocomposite }\end{array}$ & 243.11 & Freundlich & - & - & 9.2 & $15 \mathrm{~min}$ & $0.5 \mathrm{~g}$ & {$[37]$} \\
\hline 12. & $\begin{array}{l}\text { Humic acid-immobilized amine } \\
\text { modified polyacrylamide/ } \\
\text { bentonite composite (HA- } \\
\text { Am-PAA-B) }\end{array}$ & 239.564 & Freundlich & $\begin{array}{l}\text { Pseudo-second- } \\
\text { order }\end{array}$ & - & 8.0 & $3 \mathrm{~h}$ & $2.0 \mathrm{~g} / \mathrm{L}$ & {$[38]$} \\
\hline 13. & $\begin{array}{l}\text { Humic acid-immobilized amine- } \\
\text { modified polyacrylamide- } \\
\text { bentonite composite }\end{array}$ & 239.564 & Freundlich & $\begin{array}{l}\text { Pseudo-second- } \\
\text { order }\end{array}$ & - & $5.0-8.0$ & $1 \mathrm{~h}$ & $2.0 \mathrm{~g} / \mathrm{L}$ & {$[39]$} \\
\hline 6. & $\mathrm{Fe}_{3} \mathrm{O}_{4} @$ PANI nanocomposites & 240.00 & Langmuir & $\begin{array}{l}\text { Pseudo-second- } \\
\quad \text { order }\end{array}$ & Exothermic & 7.0 & $4 \mathrm{~h}$ & $0.01 \mathrm{~g}$ & {$[40]$} \\
\hline 7. & $\begin{array}{l}\text { Vinyl-modified mesoporous } \\
\text { poly (acrylic acid)/ } \mathrm{SiO}_{2}(\mathrm{PAA} / \\
\left.\mathrm{SiO}_{2}\right) \text { composite nanofiber } \\
\text { membranes }\end{array}$ & 220.49 & $\begin{array}{l}\text { Redlich- } \\
\text { Peterson } \\
\text { isotherm }\end{array}$ & $\begin{array}{l}\text { Pseudo-second- } \\
\text { order }\end{array}$ & - & - & $240 \mathrm{~min}$ & $50 \mathrm{mg} / 50 \mathrm{~mL}$ & [41] \\
\hline 8. & $\begin{array}{l}\text { Activated carbon } / \mathrm{CoFe}_{2} \mathrm{O}_{4} \\
\text { composite }(\mathrm{AC} / \mathrm{CFO})\end{array}$ & 89.29 & Langmuir & $\begin{array}{l}\text { Pseudo-second- } \\
\text { order }\end{array}$ & - & 5.0 & $5 \mathrm{~min}$ & - & {$[42]$} \\
\hline 9. & $\begin{array}{l}\text { Graphene oxide / cellulose bead } \\
\text { (GOCB) composites }\end{array}$ & 30.090 & Langmuir & $\begin{array}{l}\text { Pseudo-second- } \\
\text { order }\end{array}$ & Endothermic & 7.0 & $12 \mathrm{~h}$ & $0.1 \mathrm{~g}$ & {$[43]$} \\
\hline 10. & $\begin{array}{l}\text { Magnetoactive nanocomposite } \\
\text { fibers }\end{array}$ & 8.809 & Langmuir & - & Endothermic & 8.0 & $24 \mathrm{~h}$ & - & [44] \\
\hline 11. & $\begin{array}{l}\text { Polyaniline-nickel ferrite } \\
\text { magnetic nanocomposite }\end{array}$ & 4.09 & Langmuir & $\begin{array}{l}\text { Pseudosecond- } \\
\text { order }\end{array}$ & - & 7.0 & $210 \mathrm{~min}$ & $5.0 \mathrm{~g} / \mathrm{L}$ & [45] \\
\hline 14. & Polyaniline/ZnO nanocomposite & - & - & - & - & - & $5 \mathrm{~h}$ & $0.4 \mathrm{~g} / \mathrm{L}$ & {$[46]$} \\
\hline 15. & $\begin{array}{l}\mathrm{Fe}_{0.01} \mathrm{Ni}_{0.01} \mathrm{Zn}_{0.98} \mathrm{O} / \\
\text { polyacrylamide } \\
\text { nanocomposite }\end{array}$ & - & - & - & - & - & - & - & [47] \\
\hline 16. & Chitin beads $(\mathrm{CH})$ & 142.86 & Freundlich & $\begin{array}{l}\text { Pseudo-second- } \\
\text { order }\end{array}$ & Exothermic & 7.0 & $180 \mathrm{~min}$ & $0.1 \mathrm{~g}$ & This study \\
\hline 17. & $\begin{array}{l}\text { Nickel oxide nanoparticles } \\
\text { loaded chitin beads (NiO NPs/ } \\
\mathrm{CH})\end{array}$ & 370.37 & Langmuir & $\begin{array}{l}\text { Pseudo-second- } \\
\text { order }\end{array}$ & Exothermic & 7.0 & $180 \mathrm{~min}$ & $0.1 \mathrm{~g}$ & This study \\
\hline
\end{tabular}




\section{Conclusions}

The present study shows that the nickel oxide nanoparticles loaded chitin beads (nanocomposite) can be easily prepared and further used as an adsorbent for the removal of MG from aqueous medium. The characterization (TEM, SEM, and FTIR) evinced that the availability of the larger surface and the presence of functional groups made nanocomposite appropriate for MG dye adsorption. The results obtained from the study of various system variables indicated that the dye adsorption increases with increasing solution $\mathrm{pH}$, initial dye concentration, contact time, and dosage of adsorbent, and the optimized values were $7.0,100 \mathrm{mg} / \mathrm{L}, 180 \mathrm{~min}$, and $0.1 \mathrm{~g}$, respectively. From the non-linear chi-square statistic test, it can be concluded that the Langmuir isotherm was the best fitted adsorption isotherm model for the experimental data. The adsorption kinetics can be predicted by the pseudosecond-order kinetic model. Thermodynamic study manifested that the adsorption process was exothermic, spontaneous, and physical in nature. All the results demonstrated that the nanocomposite could be promising and effective adsorbent.

Acknowledgments The authors gratefully acknowledge the financial assistance provided by the INSPIRE Programme under the Assured Opportunity for Research Careers (AORC) scheme, funded by the Department of Science and Technology (DST) (Sanction Order No.: DST/INSPIRE Fellowship/2013/66). The authors are also thankful to Dr. Ruchita Pal-Senior Technical Assistant from Advanced Instrumentation Facility, Jawaharlal Nehru University, New Delhi, for the SEM analysis.

\section{References}

1. Khataee AR, Dehghan G, Zarei M et al (2011) Neural network modeling of biotreatment of triphenylmethane dye solution by a green macroalgae. Chem Eng Res Des 89:172-178. doi:10.1016/ j.cherd.2010.05.009

2. Zhou Y, Min Y, Qiao H et al (2015) Improved removal of malachite green from aqueous solution using chemically modified cellulose by anhydride. Int J Biol Macromol 74:271-277. doi:10.1016/j. ijbiomac.2014.12.020

3. Shirmardi M, Mahvi AH, Hashemzadeh B et al (2013) The adsorption of malachite green (MG) as a cationic dye onto functionalized multi walled carbon nanotubes. Korean J Chem Eng 30:16031608. doi:10.1007/s11814-013-0080-1

4. Méndez A, Fernández F, Gascó G (2007) Removal of malachite green using carbon-based adsorbents. Desalination 206:147-153. doi:10.1016/j.desal.2006.03.564

5. Man LW, Kumar P, Teng TT, Wasewar KL (2012) Design of experiments for malachite green dye removal from wastewater using thermolysis - coagulation-flocculation. Desalination Water Treat 40:260-271. doi:10.1080/19443994.2012.671257

6. Oladoja NA, Aliu YD (2009) Snail shell as coagulant aid in the alum precipitation of malachite green from aqua system. J Hazard Mater 164:1496-1502. doi:10.1016/j.jhazmat.2008.09.114

7. Khataee AR, Zarei M, Dehghan G et al (2011) Biotreatment of a triphenylmethane dye solution using a Xanthophyta alga: modeling of key factors by neural network. J Taiwan Inst Chem Eng 42:380 386. doi:10.1016/j.jtice.2010.08.006

8. Saha S, Wang JM, Pal A (2012) Nano silver impregnation on commercial $\mathrm{TiO} 2$ and a comparative photocatalytic account to degrade malachite green. Sep Purif Technol 89:147-159. doi:10.1016/j. seppur.2012.01.012

9. Bejarano-Pérez NJ, Suárez-Herrera MF (2008) Sonochemical and sonophotocatalytic degradation of malachite green: the effect of carbon tetrachloride on reaction rates. Ultrason Sonochem 15: 612-617. doi:10.1016/j.ultsonch.2007.09.009

10. Berberidou C, Poulios I, Xekoukoulotakis NP, Mantzavinos D (2007) Sonolytic, photocatalytic and sonophotocatalytic degradation of malachite green in aqueous solutions. Appl Catal B Environ 74:63-72. doi:10.1016/j.apcatb.2007.01.013

11. Moumeni O, Hamdaoui O (2012) Intensification of sonochemical degradation of malachite green by bromide ions. Ultrason Sonochem 19:404-409. doi:10.1016/j.ultsonch.2011.08.008

12. Zhou X-J, Guo W-Q, Yang S-S et al (2013) Ultrasonic-assisted ozone oxidation process of triphenylmethane dye degradation: evidence for the promotion effects of ultrasonic on malachite green decolorization and degradation mechanism. Bioresour Technol 128:827-830. doi:10.1016/j.biortech.2012.10.086

13. Bai C, Xiao W, Feng D et al (2013) Efficient decolorization of malachite green in the Fenton reaction catalyzed by [Fe(III)salen]Cl complex. Chem Eng J 215-216:227-234. doi:10.1016/j. cej.2012.09.124

14. Chen F, Ma W, He J, Zhao J (2002) Fenton degradation of malachite green catalyzed by aromatic additives. J Phys Chem A 106: 9485-9490. doi:10.1021/jp0144350

15. Karimi A, Aghbolaghy M, Khataee A, Shoa Bargh S (2012) Use of enzymatic bio-Fenton as a new approach in decolorization of malachite green. Sci World J 2012:e691569. doi:10.1100/2012/691569

16. Nidheesh PV, Gandhimathi R, Ramesh ST (2013) Degradation of dyes from aqueous solution by Fenton processes: a review. Environ Sci Pollut Res 20:2099-2132. doi:10.1007/s11356-012-1385-Z

17. Ravi Kumar MNV (2000) A review of chitin and chitosan applications. React Funct Polym 46:1-27. doi:10.1016/S1381-5148(00) 00038-9

18. Wei A, Liu B, Zhao H et al (2014) Synthesis and formation mechanism of flowerlike architectures assembled from ultrathin $\mathrm{NiO}$ nanoflakes and their adsorption to malachite green and acid red in water. Chem Eng J 239:141-148. doi:10.1016/j.cej.2013.10.079

19. Hussain F, Hojjati M, Okamoto M, Gorga RE (2006) Review article: polymer-matrix nanocomposites, processing, manufacturing, and application: an overview. J Compos Mater 40:1511-1575. doi:10.1177/0021998306067321

20. Wadhwani PM, Ladha DG, Panchal VK, Shah NK (2014) Enhanced corrosion inhibitive effect of p-methoxybenzylidene-4, 4'-dimorpholine assembled on nickel oxide nanoparticles for mild steel in acid medium. RSC Adv 5:7098-7111. doi:10.1039/ C4RA13390K

21. Wadhwani PM, Panchal VK, Shah NK (2015) Newly synthesized salicylidene-4,4'-dimorpholine (SDM) assembled on nickel oxide nanoparticles (NiONPs) and its inhibitive effect on mild steel in $2 \mathrm{~N}$ hydrochloric acid. Appl Surf Sci 331:373-387. doi:10.1016/j. apsusc.2015.01.105

22. Chowdhury S, Mishra R, Saha P, Kushwaha P (2011) Adsorption thermodynamics, kinetics and isosteric heat of adsorption of malachite green onto chemically modified rice husk. Desalination 265: 159-168. doi:10.1016/j.desal.2010.07.047

23. Chowdhury S, Chakraborty S, Saha P (2011) Biosorption of Basic Green 4 from aqueous solution by Ananas comosus (pineapple) leaf powder. Colloids Surf B Biointerfaces 84:520-527. doi:10.1016/j. colsurfb.2011.02.009

24. Raval NP, Shah PU, Ladha DG et al (2015) Comparative study of chitin and chitosan beads for the adsorption of hazardous anionic 
azo dye Congo Red from wastewater. Desalination Water Treat 57: 9247-9262. doi:10.1080/19443994.2015.1027959

25. Langmuir I (1918) The adsorption of gases on plane surfaces of glass, mica and platinum. J Am Chem Soc 40:1361-1403. doi:10. 1021/ja02242a004

26. Shah PU, Raval NP, Shah NK (2015) Adsorption of copper from an aqueous solution by chemically modified cassava starch. J Mater Environ Sci 6:2573-2582

27. Freundlich HM (1906) Over the adsorption in solution. J Phys Chem 57:385-470

28. Unuabonah EI, Olu-Owolabi BI, Adebowale KO, Ofomaja AE (2007) Adsorption of lead and cadmium ions from aqueous solutions by tripolyphosphate-impregnated Kaolinite clay. Colloids Surf Physicochem Eng Asp 292:202-211. doi:10.1016/j.colsurfa. 2006.06.024

29. Ahmad R, Kumar R (2010) Adsorptive removal of congo red dye from aqueous solution using bael shell carbon. Appl Surf Sci 257: 1628-1633. doi:10.1016/j.apsusc.2010.08.111

30. Santhi T, Manonmani S, Smitha T (2010) Removal of malachite green from aqueous solution by activated carbon prepared from the epicarp of Ricinus communis by adsorption. J Hazard Mater 179: 178-186. doi:10.1016/j.jhazmat.2010.02.076

31. Mittal A, Mittal J, Malviya A, Gupta VK (2009) Adsorptive removal of hazardous anionic dye "Congo red" from wastewater using waste materials and recovery by desorption. J Colloid Interface Sci 340:16-26. doi:10.1016/j.jcis.2009.08.019

32. Ali H (2010) Biodegradation of synthetic dyes - a review. Water Air Soil Pollut 213:251-273. doi:10.1007/s11270-010-0382-4

33. Wang D, Liu L, Jiang $X$ et al (2015) Adsorption and removal of malachite green from aqueous solution using magnetic $\beta$ cyclodextrin-graphene oxide nanocomposites as adsorbents. Colloids Surf Physicochem Eng Asp 466:166-173. doi:10.1016/j. colsurfa.2014.11.021

34. Pourjavadi A, Doulabi M, Doroudian M (2014) Adsorption characteristics of malachite green dye onto novel kappa-carrageenan-gpolyacrylic acid/TiO2-NH2 hydrogel nanocomposite. J Iran Chem Soc 11:1057-1065. doi:10.1007/s13738-013-0374-6

35. Li X, Li Y, Zhang S, Ye Z (2012) Preparation and characterization of new foam adsorbents of poly(vinyl alcohol)/chitosan composites and their removal for dye and heavy metal from aqueous solution. Chem Eng J 183:88-97. doi:10.1016/j.cej.2011.12.025

36. Jeon YS, Lei J, Kim J-H (2008) Dye adsorption characteristics of alginate/polyaspartate hydrogels. J Ind Eng Chem 14:726-731. doi: 10.1016/j.jiec.2008.07.007

37. Sonawane SH, Chaudhari PL, Ghodke SA et al (2009) Ultrasound assisted synthesis of polyacrylic acid-nanoclay nanocomposite and its application in sonosorption studies of malachite green dye. Ultrason Sonochem 16:351-355. doi:10.1016/j.ultsonch.2008.10.008

38. Anirudhan TS, Suchithra PS (2009) Adsorption characteristics of humic acid-immobilized amine modified polyacrylamide/bentonite composite for cationic dyes in aqueous solutions. J Environ Sci (China) 21:884-891

39. Anirudhan TS, Suchithra PS, Radhakrishnan PG (2009) Synthesis and characterization of humic acid immobilizedpolymer/bentonite composites and their ability to adsorb basic dyes from aqueous solutions. Appl Clay Sci 43:336-342. doi: 10.1016/j.clay.2008.09.015

40. Mahto TK, Chowdhuri AR, Sahu SK (2014) Polyanilinefunctionalized magnetic nanoparticles for the removal of toxic dye from wastewater. J Appl Polym Sci 131:1-9. doi:10.1002/ app. 40840

41. Xu R, Jia M, Zhang Y, Li F (2012) Sorption of malachite green on vinyl-modified mesoporous poly(acrylic acid)/SiO2 composite nanofiber membranes. Microporous Mesoporous Mater 149:111118. doi:10.1016/j.micromeso.2011.08.024

42. Ai L, Huang $\mathrm{H}$, Chen $\mathrm{Z}$ et al (2010) Activated carbon/CoFe2O4 composites: facile synthesis, magnetic performance and their potential application for the removal of malachite green from water. Chem Eng J 156:243-249. doi:10.1016/j.cej.2009.08.028

43. Zhang X, Yu H, Yang $\mathrm{H}$ et al (2015) Graphene oxide caged in cellulose microbeads for removal of malachite green dye from aqueous solution. J Colloid Interface Sci 437:277-282. doi:10. 1016/j.jcis.2014.09.048

44. Savva I, Marinica O, Papatryfonos CA et al (2015) Evaluation of electrospun polymer-Fe3O4 nanocomposite mats in malachite green adsorption. RSC Adv 5:16484-16496. doi:10.1039/ C4RA16938G

45. Patil MR, Shrivastava VS (2014) Adsorption of malachite green by polyaniline-nickel ferrite magnetic nanocomposite: an isotherm and kinetic study. Appl Nanosci 1-8. doi: 10.1007/s13204-0140383-5

46. Eskizeybek V, Sarı F, Gülce H et al (2012) Preparation of the new polyaniline $/ \mathrm{ZnO}$ nanocomposite and its photocatalytic activity for degradation of methylene blue and malachite green dyes under UV and natural sun lights irradiations. Appl Catal B Environ 119-120: 197-206. doi:10.1016/j.apcatb.2012.02.034

47. Kant S, Pathania D, Singh P et al (2014) Removal of malachite green and methylene blue by $\mathrm{Fe} 0.01 \mathrm{Ni} 0.01 \mathrm{Zn} 0.98 \mathrm{O} /$ polyacrylamide nanocomposite using coupled adsorption and photocatalysis. Appl Catal B Environ 147:340-352. doi:10. 1016/j.apcatb.2013.09.001 